\title{
Structural modeling in object-oriented based software by utilizing data tables
}

\author{
Zafer Yılmaz $^{* 1 \text { iD }}$, Fatih Yesevi Okur ${ }^{1}$ iD, Murat Günaydın' ${ }^{\text {iD }}$, Ahmet Can Altunışık ${ }^{1}$ (D) \\ ${ }^{1}$ Karadeniz Technical University, Department of Civil Engineering, Trabzon, Turkey
}

\begin{abstract}
Engineering software running on object-oriented programming language has been extensively used in structural modeling past 20 years. Taking their ease of use and a large area of utilization into account, these software will be used by engineers. Moreover, a number of these software increases, and many enhancements take place. Considering the developments in modeling software, data transition is much needed for model updates. Data transition between these software is widely studied and many methods have been developed. However, if an engineering model is inaccessible or not created in the first place, available data reports can be used to create an object-oriented based model. In this study, it is aimed to utilize the Interactive Database Editing interface on SAP2000 to create a model by using data tables.
\end{abstract}

\section{Keywords}

Civil engineering; Data tables; Interactive database editing; Structural modeling; Object-oriented based software

Received: 01 December 2021; Accepted: 24 December 2021

ISSN: 2630-5771 (online) $\odot 2021$ Golden Light Publishing All rights reserved.

\section{Introduction}

The problem-solving mindset has been the main initiator of great advances in human history. From the smallest objects used in daily life to inventions that changed the lives of millions, the main priority was to protect and ease human life. This progress starts with the detection of the problem and ends with a well-prepared solution. However, endless advancement continues by finding flaws of previous solutions and creating a better solution. Engineers are the pioneers of problem-solving and they are responsible for advances in many important areas such as structural safety. Developments in engineering design and changes in environmental conditions enforced creating an object-oriented based model of existing structures to re-analyze them under new load values and detect inadequate structure members [1]. Fig. 1 shows old structures built before computer-aided design and object-oriented based software such as SAP2000, ETABS, Tekla and Revit were utilized in construction technology.

Engineers often face a lack of information dealing with existing structures because data gets lost in time or is in other formats such as old software files and reports. Therefore time-saving and practical ways used for remodeling gained importance [2]. Laser scanning, ground penetration, image-based modeling are some of the technological approaches studied by many researchers on different types of structures [3-7]. However, modeling through the utilization of data tables within reports has not been studied.

\footnotetext{
* Corresponding author

Email: zafer.yilmaz@ktu.edu.tr
} 

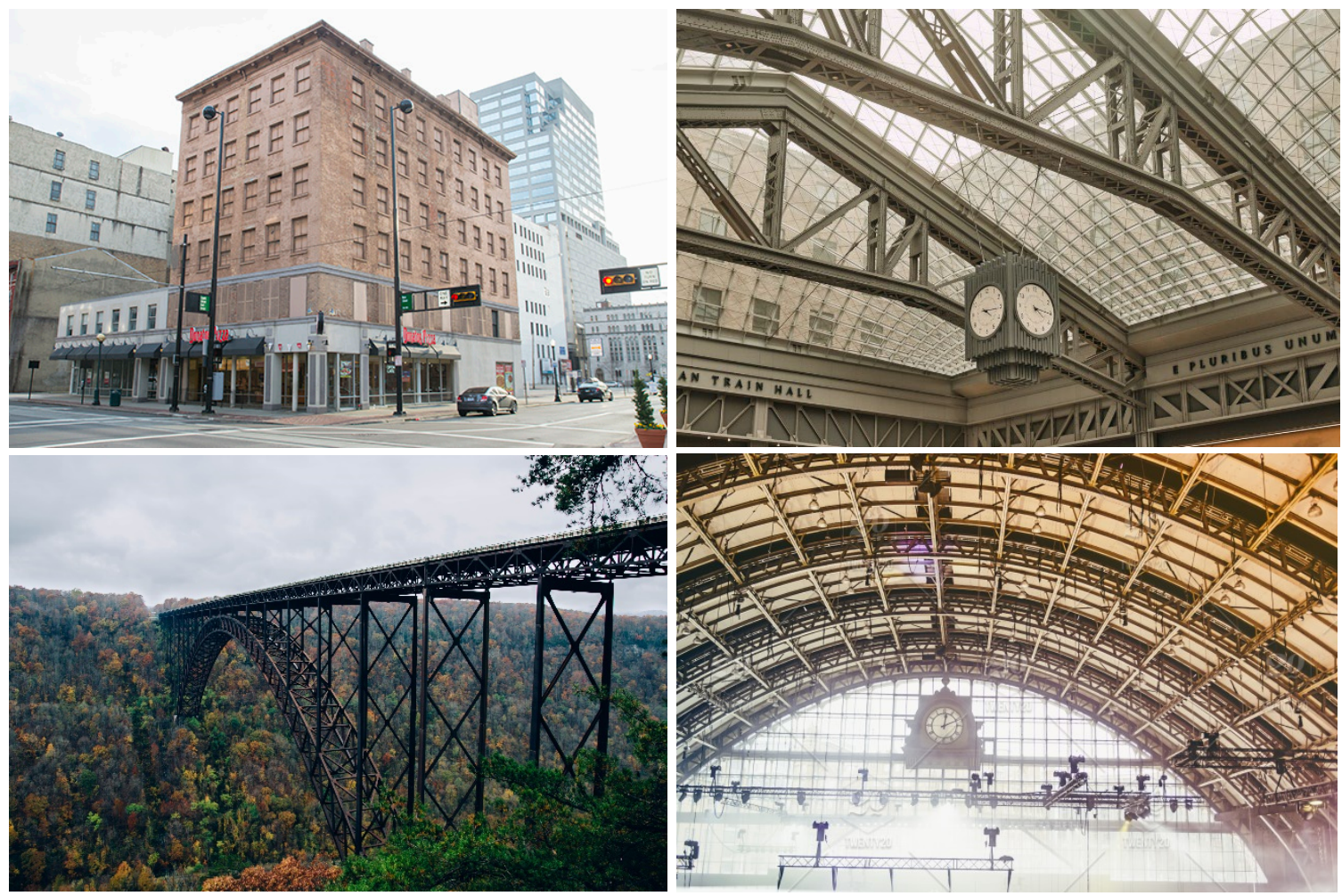

Fig. 1. Old structures built before CAD software (retrieved from the internet)

In this study it is aimed to utilize data tables presented in reports and create an object-oriented based model thus allowing going over the results of analyses presented in the report and testing the robustness of structures under updated load values. Besides, if retrofitting is required, created model could be used in decision making. Interactive Database Editing (IDE) interface on SAP2000 software is utilized for a fast and smooth transition from data tables to object-oriented based models (Fig. 2)[8].

\section{Structural modeling in object-oriented based software}

Model dimensions, materiel properties, loads, and much more information of a completed analysis are stored in reports and printouts. This information needs to be transformed into a proper format to be used in Interactive Database Editing. Then, by using tables for interactive editing and importing related data sequentially, the model gets completed. The modeling process is given in Fig. 3.

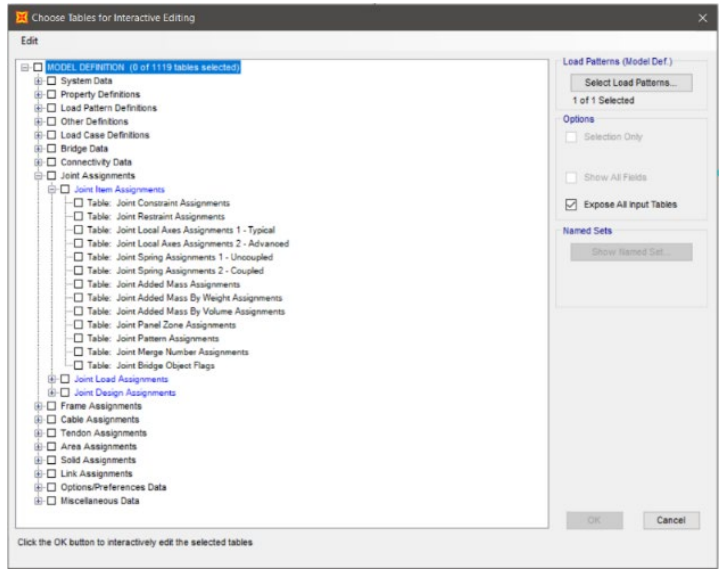

Fig. 2. The interactive database editing interface

Upon opening Interactive Database Editing, 33 tables are shown in which users can enter basic model data. However, these 33 tables generally are not enough to completely model the project at hand. For this reason, "Expose All Input Tables" from the options on the right side is required to be activated to open more input tables. 


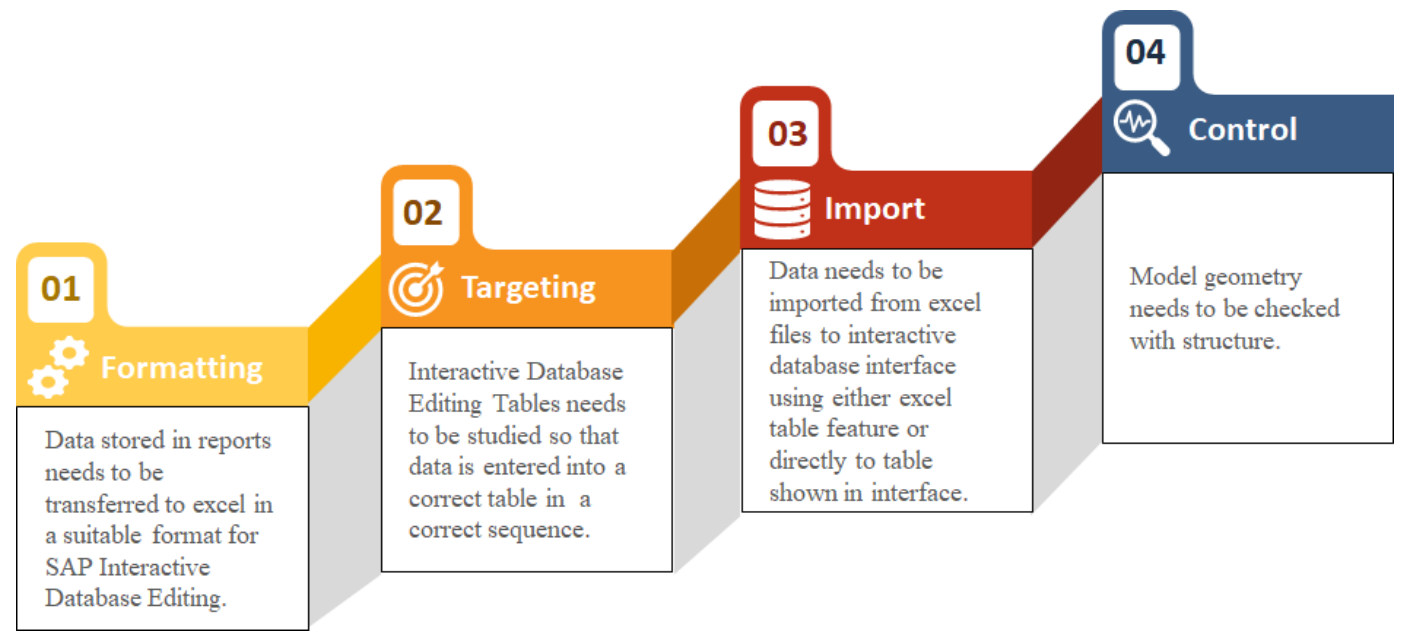

Fig. 3. Modeling steps

The selection of tables to be used among 1119 tables presented on the interface can be timeconsuming and may result in inaccurate modeling. Therefore it is essential to filter out unnecessary tables and focus on the relevant tables. 16 categories and a total of 1119 tables appear from which required tables can be found and used. Those 16 categories and their general utilization areas are presented in Table 1.

Importing model data can be complicated since each table within the IDE has its unique layout and data to be imported can be in a different layout. The editing table for joint coordinates and frame connections can be seen in Fig. 4. Each table has additional options which might be needed based on the model. It is suggested to use the presented Excel option in the IDE interface for significantly big projects since editing data on the interface causes it to freeze or close because changes made on the interface are directly applied to the model.

\section{Selected model as a numerical example}

\subsection{Definition of model}

This study covers the modeling of the Space Frame System of Sports Center built by the Ministry of Youth and Sports in Dernekpazarı, Trabzon (Fig. 5). Modeling is carried out by using technical reports as a source of information. Thus, structural status assessment is carried out without detailed investigation of structural members which is timeconsuming and risky to some extent. The area of the roof is $1246 \mathrm{~m}^{2}$ and the height of the space frame system is $0.836 \mathrm{~m}$ at the highest point.

Material properties, joints, frames, restraint and frame assignments, load cases, load combinations, and load values of the model are first taken from the report, then formatted on excel and imported to SAP2000 by using the Interactive Database Editing interface. Space Frame System consists of 469 joints, 11 different types of frame sections totaling up to 1776 frames. The performed analysis presented in the report had 22 load cases and 319 load combinations.

Since the space frame system consists of steel members made of only S235 material, the material property can be easily added to SAP2000 without Interactive Database Editing. However, using IDE in projects with multiple material properties can reduce the workload. The schematic of model creation from reports to the final model is shown in Fig. 6. From step one to step two each data table is selected and formatted on different excel files so that it is organized and more readable. Then, these organized excel files are imported into the Interactive Database Editing interface in order, resulting in an object-oriented based model shown in the fourth step. 
Table 1. Interactive database tables and their utilization areas

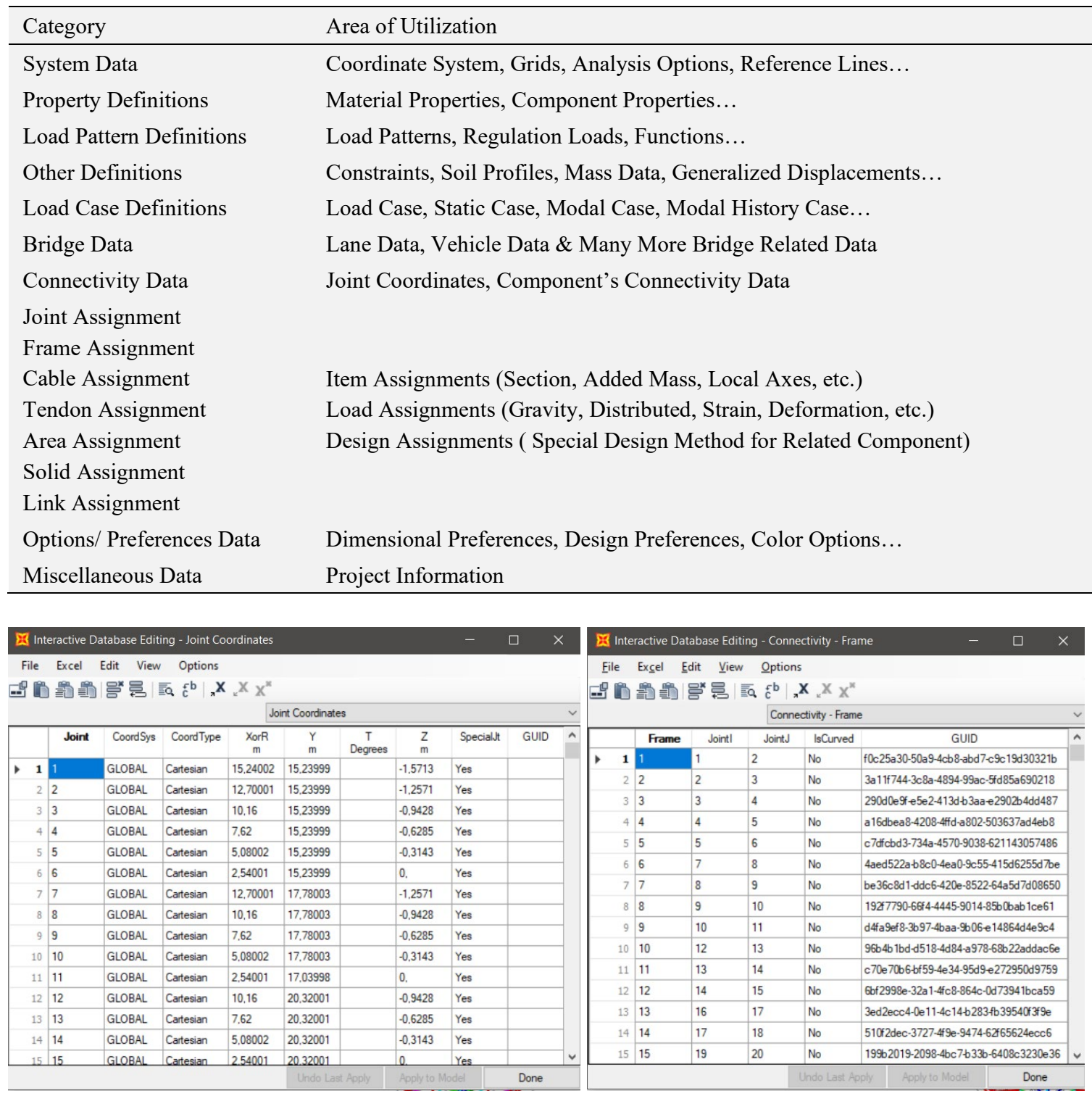

Fig. 4. Data input tables on the interactive database editing interface
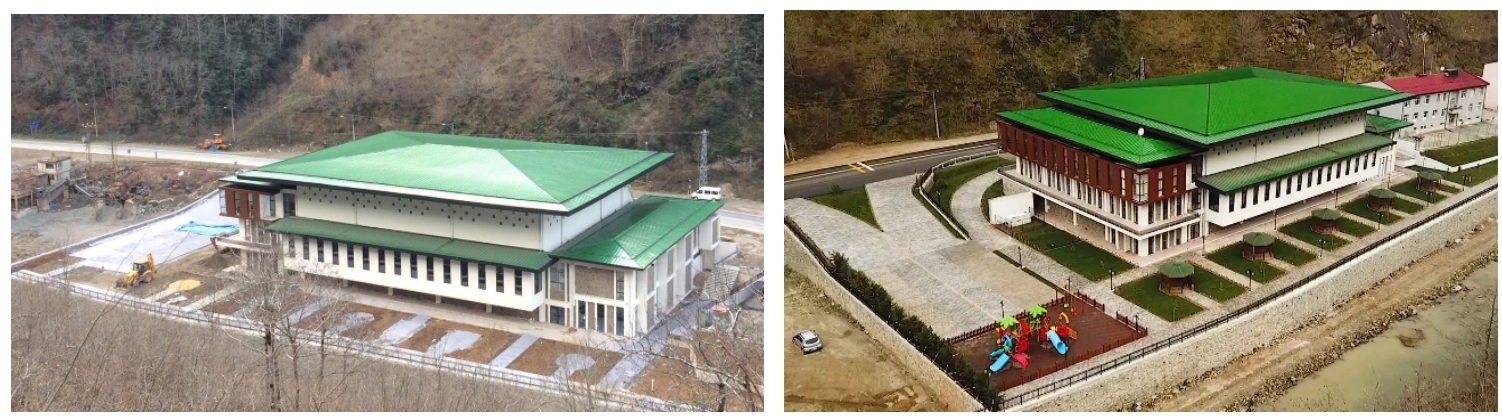

Fig. 5. Dernekpazarı sport center 


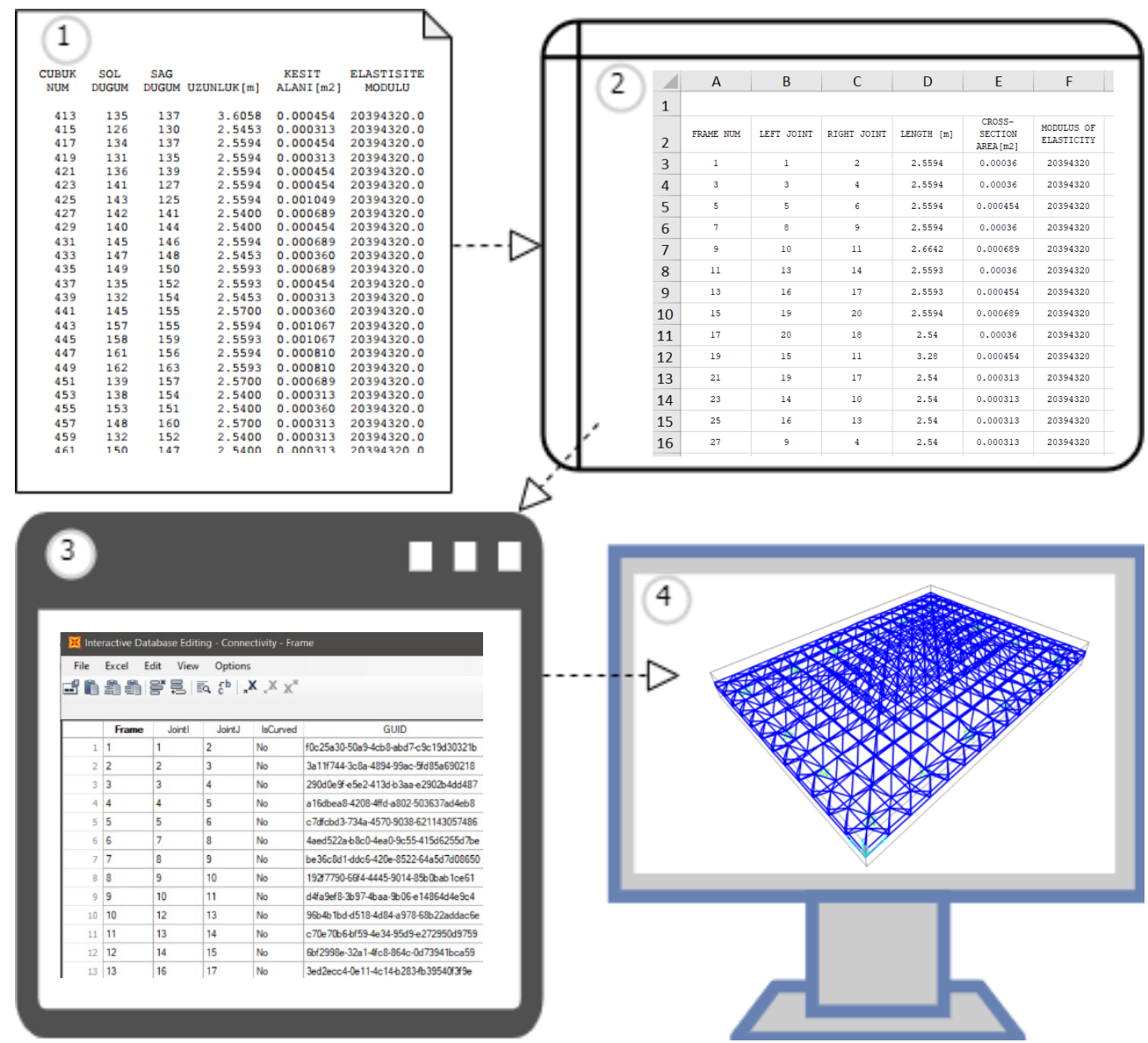

Fig. 6. Schematic of the remodeling process

\subsection{Challenges of remodeling and solutions}

This project includes modeling of a Space Frame System of Sports Center located in Dernekpazar1 Trabzon. In this case, the only source of information was reports of the analysis and results presented on the same report. The problems of modeling a structure only by reports and solutions to these problems are summarized below:

- Collecting information related to the model was time-consuming in first hand considering the variation in cross-sections and number of frames. Besides, members at the center of the space frame system are hard to reach for examination because of height and lack of mobility systems. Therefore, the model created on interactive database editing is compared with pictures taken on-site (Fig. 7). Moreover, a faulty coordinate for joints or wrong connections can easily be detected on SAP2000.

- Reports are the primary form of submitting results of structural analysis since engineering software is not commonly used. However, in the case of remodeling, simply organized reports are not effective sources of data. Nevertheless, reports can be the only source of information of built structures such as in this case. Data tables presented in reports were not grouped, listed, or ordered. Therefore each table is formatted separately and stored in different excel files to reduce the workload and risk of error.

- Matching each data table to its corresponding table on the interactive database editing interface and following the correct sequence plays a critical role in correct modeling. For this reason, previously separated data tables are studied and proper sequence is determined. 


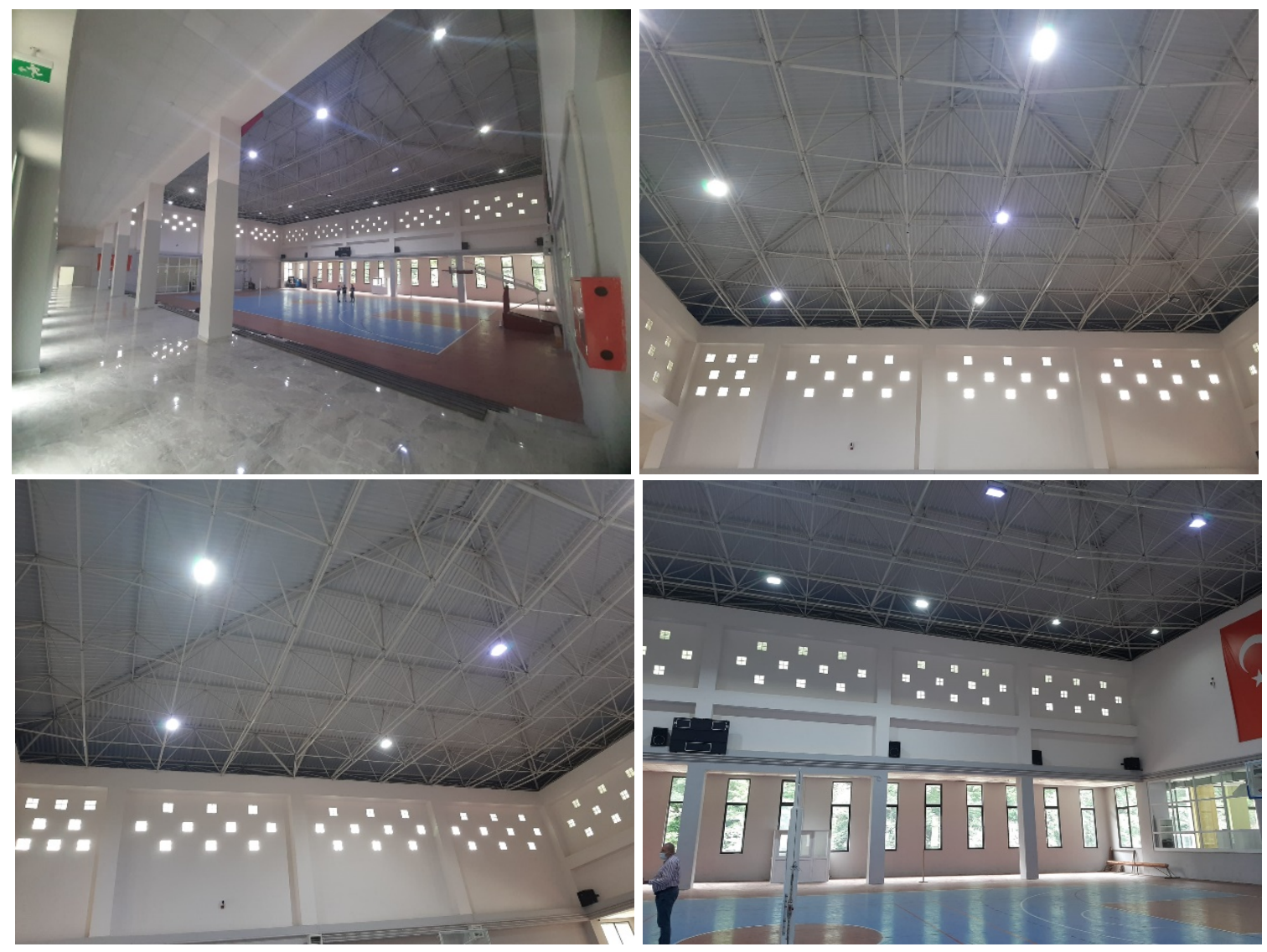

Fig. 7. Pictures of the space frame system
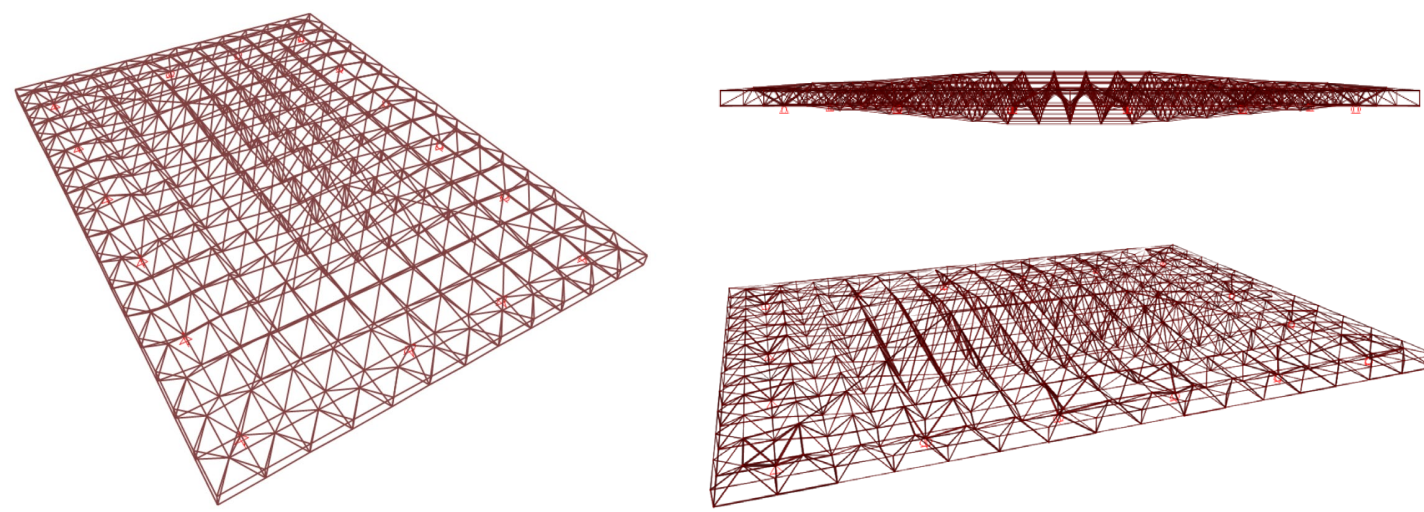

Fig. 8. Model geometry in SAP2000

This sequence is respectively material properties, joints, frames, restraints, load cases, load combination, joint loads, frame loads, etc. The geometry of the space frame system formed on SAP2000 software is shown in Fig. 8.

\section{Conclusions}

This study aims to enlighten an existing Interactive Database Editing interface on SAP2000 for it to be used in a troublesome situation such as re-modeling without any CAD file. In the case of modeling a 
structure by using reports, engineers mostly face difficulties in converting the data and creating a CAD model. This mostly results in a full physical investigation of structure and unfortunately inevitable assumptions for hard-to-reach parts. These ordinary methods are time and moneyconsuming compared to represented study. This method is the fastest and most efficient way to model a structure in cases of reports being the only source of information.

\section{Declaration of conflicting interests}

The author(s) declared no potential conflicts of interest with respect to the research, authorship, and/or publication of this article.

\section{References}

[1] Ma Z (2012) The realization of nonlinear architectural on the parametric model. Physics Procedia 25: 1470-1475.

[2] Monitoring and safety evaluation of existing concrete structures. Lausanne, Switzerland: International Federation for Structural Concrete, 2003.

[3] Lubowiecka I, Armesto J, Arias P, Lorenzo H (2009) Historic bridge modeling using laser scanning, ground-penetrating radar, and finite element methods in the context of structural dynamics. Engineering Structures, 31(11), 26672676. doi:10.1016/j.engstruct.2009.06.018
[4] Fassi F, Fregonese L, Ackermann S, De Troia V (2013) Comparıson between laser scanning and automated $3 \mathrm{~d}$ modelling techniques to reconstruct complex and extensive cultural heritage areas. The International Archives of the Photogrammetry, Remote Sensing and Spatial Information Sciences, XL-5/W1, 73-80. doi:10.5194/isprsarchives-xl-5w1-73-2013

[5] Castellazzi G, D’Altri A, Bitelli G, Selvaggi I, Lambertini A (2015) From laser scanning to finite element analysis of complex buildings by using a semi-automatic procedure. Sensors 15(8): 18360 18380. doi: $10.3390 / \mathrm{s} 150818360$

[6] Yang H, Xu X, Neumann I ( 2014) The benefit of $3 \mathrm{~d}$ laser scanning technology in the generation and calibration of fem models for health assessment of concrete structures. Sensors 14(11): 21889-21904. doi:10.3390/s141121889

[7] Yang H, Xu X, Neumann I (2016) Laser scanningbased updating of a finite-element model for structural health monitoring. IEEE Sensors Journal 16(7): 2100-2104. doi:10.1109/jsen.2015.2508965

[8] CSI, "SAP2000 Integrated Software for Structural Analysis and Design," Computers and Structures Inc., Berkeley, California 